Research Article

\title{
Nonlinear Effect Analysis of Electricity Price on Household Electricity Consumption
}

\author{
Lianwei Zhang $(\mathbb{D}$ and Xiaoni Wen \\ School of Economics \& Management, Xidian University, Xi'an, China \\ Correspondence should be addressed to Lianwei Zhang; lwzhang2017@163.com
}

Received 20 August 2020; Revised 2 October 2020; Accepted 26 March 2021; Published 10 April 2021

Academic Editor: Wei-Chiang Hong

Copyright (c) 2021 Lianwei Zhang and Xiaoni Wen. This is an open access article distributed under the Creative Commons Attribution License, which permits unrestricted use, distribution, and reproduction in any medium, provided the original work is properly cited.

\begin{abstract}
The household energy consumption has been a hot field in the study of household energy consumption in recent years. With the increase of residents' income level and the pushing of urbanization, there is a complex nonlinear relationship between energy price and energy consumption. The purpose of this paper is to investigate the scenario effect of per capita income and regional differences in urbanization development on the relationship between electricity sales price and urban household electricity consumption. To this direction, based on the regional characteristics of economic development in China, with the residents' disposable income and the urbanization level as the conversion variables and the electricity sales price as the core explanatory variable, the panel smooth transition regression (PSTR) model of electricity sales price and urban household electricity consumption from the perspectives of income level and urbanization has been constructed in this paper. The empirical results show the following: (1) Under the consideration of regional difference of residents' income level, with the increase of residents' disposable income level, there is a significant negative correlation between electricity sales price and urban household electricity consumption in the whole country, the eastern region, and the central region, while such correlation is significantly positive in the western region. (2) Under the consideration of the difference of urbanization development level, the national regional electricity sales price and the urbanization level are positively related to the urban household electricity consumption, and the urbanization level in the western region plays the biggest role in promoting the urban household electricity consumption, followed by the eastern region and then the central region which plays the smallest role. This paper discusses the effect of electricity sales price on urban household electricity consumption from the perspective of regional difference in income and urbanization, which provides the decision-making basis and empirical support for developing regional electricity price policy and household energy consumption policy.
\end{abstract}

\section{Introduction}

With the rapid development of urbanization and industrialization, China's economy has entered a new normal stage, and its economic growth has turned into an important historical phase shifting from high-speed to highquality development. As a strong and basic support of economy development, energy consumption has been widely paid attention to and discussed. In recent years, the residents' energy consumption has become an important economic sector for the growth of total energy consumption in China. Meanwhile, with the annually increasing economic level and urbanization, China's urban household energy consumption is also increasing; in particular, the growth of energy demand for electricity has become a significant source of household energy consumption. The report of the 19th National Congress of the Communist Party of China points out that the market direction of China's energy consumption is to "drive the revolution of energy production and consumption and build a clean, low-carbon, safe and efficient energy system". Therefore, in the new normal stage of China's economic development, studying energy consumption characteristics and influencing factors of urban households is helpful for policy makers and governments to realize the green and sustainable development. 
On the other hand, the geographic variation and the stage characteristics of economic development facing Chinese residents are also the influencing factors causing objective differences in energy consumption behavior of urban households in China. First, there are differences in temperature, production habits, cultural habits, and other social perspectives in the east-west and north-south regions of China, which leads to regional differences in energy consumption. Since the reform and opening-up, China's economic development has gradually formed a pattern of developed coastal regions and relatively undeveloped central and western regions, and this is reflected in regional income level (i.e., higher income and consumption level in the eastern and coastal regions and lower ones in the western regions). Meanwhile, the Chinese urban-rural dual economic structure also makes the issues on household energy consumption face more complex economic background and human characteristics.

The influencing factors of household energy consumption mainly include the climate characteristics, the household income, and the regional cultural traditions [1, 2]. The Report on China's Household Energy Consumption (2016) (hereinafter referred to as the report) [3] indicates that per capita energy consumption quite varies from south to north. Per capita energy consumption in the south is $291.35 \mathrm{~kg}$ standard coal/year, and that in the north is 1.68 times the per capita level in the south. Since 2000, energy consumption in household sector has grown rapidly, from 467 million tons of standard coal in 2000 to 501 million tons of standard coal in 2015 , with an annual average growth rate of $7.6 \%$, while per capita energy consumption at the same time has also increased from $126.44 \mathrm{~kg}$ of standard coal in 2000 to $365.4 \mathrm{~kg}$ of standard coal in 2015, with an annual average growth rate of $7.3 \%$. However, compared to developed countries, such as UK and USA, China's household energy consumption only corresponds to one-third of that in the USA and one-half of that in the UK.

Therefore, it is necessary to explore specific influencing factors of China's household energy consumption. This research can provide valuable reference for further improving China's regional energy governance policies and realizing the objective of energy conservation and emission reduction. The organization of this paper is as follows: Section 2 summarizes the relevant literature and presents the research basis of this paper. Section 3 designs the research, including model construction, research variables, and data source. Section 4 provides empirical analysis and results. Section 5 makes conclusion discussion and policy meaning analysis. Section 6 summarizes this study.

\section{Literature Review}

In recent years, these are growing interest and discussions about the issues of household energy consumption [4]. The demand of electricity consumption, as one of the clean energy sources, has been growing rapidly, partly because of its substitutability for other unclean energy sources. China's "West-to-East Power Transmission Project" reflects the imbalance in power demand. In the following section, we will review previous research on spatial characteristics, influencing factors, and the guarantee measures of energy demand.

First, the energy demand and the economic growth are important socioeconomic indicators for social and economic operation. There is dynamic change process of regional difference for the relationship between energy consumption and economic development. Due to the difference of resource endowment in different regions, China's energy supply pattern varies from region to region, characterized by regional difference and shifting of center of energy production and consumption, as well as rate change [5]. Second, in terms of the drivers of energy consumption, regional economic development plays a greater role in affecting energy consumption in household sector, and this is mainly related to the change of China's economic center [6]. Zhang et al. [7] study the factors that influences the shift of the center of China's oil production and consumption and find that the infrastructure and demand have a great impact on oil consumption in different regions over different periods, so that there has been the change of the center of natural gas consumption. Finally, the urbanization, industrialization, residents' income, cultural characteristics, and regional climate are all the social influencing factors at the household energy consumption level $[8,9]$. All the studies above have reflected the impact of urbanization, industrialization, and regional differences on energy consumption only under group studying with certain classification criteria, but they have not made study from unified perspective.

For the difference in intraregional growth of electricity consumption in China, Liu et al. [10] point out that the annual average growth of electricity consumption in Northeast China is the lowest, while that in Northwest China is the highest. Therefore, the dynamic change process and characteristics of the center of power demand and consumption are important considerations in the energy infrastructure. Of course, intraregional economic scale and investment scale are also important to drive the growth of electricity consumption. Due to the difference of power consumption intensity and investment efficiency, the drivers of energy consumption are different across regions. Therefore, the study of regional differential management based on influencing factors is important theoretical support and reference for energy policy making.

The rebound effect of electricity consumption is an important influencing aspect of residents' electricity consumption. Su [11] explores the maintenance level and influencing factors of rebound effect from a micro perspective and finds that the improvement of power consumption efficiency will raise the expected power saving quantity by $43.51 \%$. The author points out that the rebound effect of electricity consumption is both closely related to per capita income and significantly related to gender difference. For this, the relationship of the rebound effect of residents' income level and electricity consumption is shaped by an inverted " $V$," and that of male consumers is higher than that of female consumers. From the analysis of indirect rebound effects of main energy consumption, including electricity, gasoline, and natural gas, the rebound effects of these three 
kinds of energy consumption are all below $10 \%$ over the period 1997-2012, but the indirect rebound effect of energy consumption has a difference between energy type and urban and rural areas. In these three types of energy consumption, the indirect rebound effect of electricity consumption is the largest [12]. The rebound effect of energy consumption determines the limitation of energy consumption reduction caused by energy efficiency improvement [13]. Given the experience of the developed countries, the rebound effect of energy consumption makes it difficult to predict the relationship between energy efficiency and energy saving effect. The rebound effect would partially offset the energy saving achieved for increased energy efficiency [14].

Energy price, income, urbanization, and industrialization are very important factors in investigating energy consumption in household sector. Liu et al. [15] have demonstrated the key effect of economic measures on residents' willingness to save energy based on Beijing, Hangzhou, Guangzhou, and Guiyang residents' household electricity consumption behavior and the economic intervention effect analysis, while the change of electricity price played a significant role in reducing residents' electricity consumption. There is difference in energy saving consciousness among different income groups. With the improvement of income level, the electricity consumption of low-grade consumption residents has shown an increasing trend. Yang et al. [16] studied the effect of residents' income and urbanization level on urban residents' appliances consumption and found that the income level and urbanization rate had positive impact on residents' appliances consumption, which led to the increase of household energy consumption. In recent years, the rapid promotion of urbanization has become an important driving factor for growth of energy consumption in household sector. It is found that the economic development, economic structure, urbanization, and income all have positively affected total electricity consumption, and the contribution rate of urbanization to electric power growth is the most significant [17].

Demand policy of electricity consumption in China relates to the electricity price system, the electricity sales price subsidy, and other aspects. Since the implementation of the stepped incremental electricity price policy for household electricity consumption in July 2012, the distribution and utilization of electricity resources have become more reasonable, and this has improved the efficiency of electricity consumption and guaranteed the limited range of equity and other multiple goals [18]. However, under the background of the improvement of overall income level of residents, there is a significant difference in the energy saving effect and difference between low-income and high-income groups [19]. With the development of the market-oriented reform of electricity price, the elimination of hidden crosssubsidization that distorts electricity price has become the necessary goal of the market-oriented reform of electricity price. The goal is to make the income of electric power enterprises more reasonable without damaging the ability of residents to pay for consumption, and simultaneously to significantly reduce the emission of electric power industry. Therefore, the objects of electricity price marketization reform are more concentrated on low-income residents, and this is an efficient and fair market-oriented electricity consumption subsidization mechanism [20].

China's electricity consumption has been characterized by periodic path evolution [21]. With the rise of energy economics in the 1970s, the studies on power economics phenomenon, especially on the relationship between power demand and economic growth in developing countries, have gradually become the focus of the academic circles at home and abroad. The existing studies have mainly formed the following views: first, the power consumption has become a one-way Granger cause of economic growth [22]; second, the economic growth has become a one-way Granger cause of power consumption [23]; third, there has been a Granger cause relationship between power consumption and economic growth [24]; fourth, there has been difference in the causal relationship between them in different situations $[25,26]$. Since the income level and life style of urban and rural residents are quite different, the characteristics and patterns of household electricity consumption in Northwest China are also significantly different. The electric consumption has obvious stepped change characteristics from rural areas to small cities, medium cities, and big cities. The demand level of rural household electricity is relatively lower, and it is mainly used for the most basic lighting, cooking, and entertainment, while that of urban household electricity is relatively higher, and it is especially used for the pursuit of life convenience, cleanliness, and comfort. Zeng et al. [27] pointed out that electricity consumption between urban and rural and among regions in China has reached a fair level after the exploration on the fairness of electricity consumption. Meanwhile, due to the difference in China's regional economic development, population scale, and other aspects, it is necessary to develop relevant electricity policies suitable for the actual situation of local regions. Ma et al. [28] explored the two behavioral mechanisms of rational decision-making and inertia decision-making in the process of residents' power consumption based on the perspective of residents' rational consumption. It has been found that income affects significantly residents' electricity consumption, and living habits have an important impact on consumption behavior [29]. However, economic development makes residents' income increase with stage characteristics; these features of changes in income have not been considered adequately in research with respect of energy consumption behavior.

In conclusion, the existing studies on household energy consumption are relatively systematic. Accordingly, many results can been summarized: (1) The household energy has regional characteristics (obviously seen in eastern, middle, and western China). (2) The impacts of influencing factors of household energy consumption and their degree vary from region to region. (3) The impact of economic development, such as industrialization and urbanization, on household energy consumption plays a role of external regulation and changes the environment of the study of the relationship between subjects. Overall, there is still necessity for further 
expansion in the existing studies, and it could be reflected in the following aspects: (1) the way to put the study of unified influence relationship in different regions and develop the evolution characteristics of variable relationship; (2) considering the same external influence factors to study the characteristics of the relationship between variables. Therefore, based on the core relationship between the price and quantity of household energy consumption, this paper investigates the external action mechanism of the change of household income and the level of urbanization promotion on their relationship, and then a systematic analysis of urban household (electric) energy consumption in China is made.

\section{Study Design}

3.1. Model. The IPAT equation, presented firstly in the 1970 s, identified three factors that determine the human environmental impact by using the equation formula $I=P \times A \times T$, with impact $(I)$, population $(P)$, affluence $(A)$, and technology $(T)$ [30]. IPAT method provides a theoretical basis for analysis of energy and environmental problems. For the STIRPAT model developed subsequently, the study on expansibility has also been made based on the idea of IPAT model. Among them, $I, P, A$, and $T$ represent the observed environmental impact, population scale, wealth, and technological progress, respectively. Owing to the different effects of household income, urbanization, and other factors on residents' energy consumption in different regions, it may be nonlinear and there is a threshold value. The transformation of traditional STR model in handling of related problems is nonsmooth. The panel smooth transition regression (PSTR) model is improved based on the traditional model, which can both describe the heterogeneity of model regression coefficient on the section and realize the smooth transition among different regions, so that the nonlinear characteristics of variables can be captured well, and it is more in line with the performance of the relationship between real economic variables. The biggest difference between panel smooth transformation regression (PSTR) model and panel threshold regression model lies in the following: (1) With panel threshold regression analysis, different groups are distinguished according to the observed values, and the boundaries between groups are obvious and discontinuous. However, this strict limitation does not always fit the real-world situation. (2) The panel smooth transformation model relaxes this restriction. The boundary is a function of the threshold variable and can fluctuate within a certain range. Panel smooth transformation model is a generalization of panel threshold regression model, which is more in line with economic and social reality.

The traditional panel fixation effect and the random effect model have difficulties in accurately measuring individual difference between explanatory variable and explained variable. For this, Hansen (1999) [31] proposed a panel threshold regression (PTR) model by introducing threshold variable $q_{i t}$ and transition function.

$$
y_{i t}=\alpha_{i}+\beta_{0}^{\prime} x_{i t} I\left(q_{i t} \leq c\right)+\beta_{1}^{\prime} x_{i t} I\left(q_{i t}>c\right)+u_{i t}
$$

Because transition function is an indicative function, there are only two conditions for valuing regression coefficient vector, $\beta_{0}$ or $\beta_{1}$, and this depends on whether the value of the threshold variable $q_{i t}$ is greater than the critical value $c$. This means that even if some individual $q_{i t}$ values are very close, there will be significant differences in the corresponding regression coefficient values (either $\beta_{0}$ or $\beta_{1}$ ) for their distribution on both sides of $c$. This jumpy change reduces the applicability of PTR model.

To avoid this, González et al. [32] set the transition function in the form of Logistic function and proposed the panel smooth transition regression (PSTR) model. The model and its transition function are as follows:

$$
\begin{gathered}
y_{i t}=\alpha_{i}+\beta_{0}^{\prime} x_{i t}+\beta_{1}^{\prime} x_{i t} g\left(q_{i t} ; \gamma, c\right)+u_{i t}, \\
g\left(q_{i t} ; \gamma, c\right)=\left[1+\exp \left(-\gamma \prod_{j=1}^{m}\left(q_{i t}-c_{j}\right)\right)\right]^{-1}, \\
\gamma>0, c_{1} \leq c_{1} \leq \cdots \leq c_{1},
\end{gathered}
$$

where $g\left(q_{i t}, \gamma, c\right)$ is transition function; $q_{i t}$ is threshold variable, and its value range is $[0,1] ; \gamma$ is smoothing coefficient, which determines transition speed; $c$ is critical value; and $m$ is the number of critical values. Since $g\left(q_{i t}, \gamma, c\right)$ is a continuous function of $q_{i t}$, and the regression coefficient vector $\beta_{0}+\beta_{1}\left(q_{i t}, \gamma, c\right)$ is also a continuous function of threshold variable, there is no jumpy change. PSTR model consists of a linear part $\left(\alpha_{i}+\beta_{0}^{\prime} x_{i t}\right)$ and a nonlinear part $\beta_{1}^{\prime} x_{i t}\left(q_{i t}, \gamma, c\right)$. The linear part is the first partition of the model. Each transition function corresponds to a new system, and (2) is a PSTR model containing two systems. The general expression of PSTR model is

$$
y_{i t}=\alpha_{i}+\beta_{0}^{\prime} x_{i t}+\sum_{j=1}^{r} \beta_{j}^{\prime} x_{i t} g_{i}\left(q_{i t}^{(j)} ; \gamma_{j}, c_{j}\right)+u_{i t} .
$$

The general expression (4) of PSTR model includes $r+1$ partitions. Then, the PSTR model corresponding to (4) is equivalent to the PTR model of Hansen (1999). When $\gamma \longrightarrow 0$, the PSTR model corresponding to (4) is equivalent to the panel fixation effect regression model. Finally, in (3), $\gamma>0, C_{1} \leq C_{2} \leq \cdots \leq C_{m}$ is a constraint to estimate the regression coefficient.

In this paper, the PSTR model has been used for identifying the nonlinear characteristics between the urban household electricity consumption and electricity sales price. As a threshold model, PSTR meets the nonlinear relationship between the total electricity demand and the price, and the specific form of PSTR model in the study is as follows:

$$
y_{i t}=\alpha_{i t}+b_{1} x_{i t}+b_{2} x_{i t} g\left(q_{i t} ; \gamma, c\right)+\varepsilon_{i t},
$$

where $\alpha_{i t}$ is the intercept; $\varepsilon_{i t}$ is the residual term; and $\gamma$ is the transition speed, which reflects the speed from " 0 " state to " 1 " state; when the value tends to be 0 , PSTR model will degenerate into the traditional linear regression model, and the nonlinear relationship between the variables is not observed. This parameter affects the smoothness of the model. $c$ is smooth parameter value, which represents the 
turning point of state change. $q_{i t}$ is the transition variable, and it can be any explanatory variable, combination form, or any other exogenous variable. The specific form of the transition function in the model is

$$
g\left(q_{i t} ; \gamma, c\right)=\left\{1+\exp \left[-\gamma \prod_{j=1}^{m}\left(q_{i t}-c_{j}\right)\right]\right\}^{-1},
$$

where $\gamma>o, c_{1} \leq c_{2} \leq \cdots \leq c_{m}, 0 \leq g\left(q_{i t} ; \gamma, c\right) \leq 1$, and the function value of $x_{i t}$ is smooth between $b_{1}$ and $b_{1}+b_{2}$. Usually, $m=1$ or $m=2$. When $m=1, g\left(q_{i t} ; \gamma, c\right)=[1+$ $\left.\exp \left[-\gamma\left(q_{i t}-c\right)\right]\right]^{-1}$, and $g\left(q_{i t} ; \gamma, c\right)$ has a location parameter; at this time, $\lim _{q_{i t} \longrightarrow-\propto} g\left(q_{i t} ; \gamma, c\right)=0$ (and $\lim _{q_{i t} \longrightarrow+\propto} g$ $\left.\left(q_{i t} ; \gamma, c\right)=1\right)$. When the transition function value is 0 , the model is called low mechanism; the model is called high mechanism if transition function value is 1 . When the transition function value is between 0 and 1 , the corresponding model is smoothly converted between these two mechanisms. When $m=2$, there are two location parameters of $g\left(q_{i t} ; \gamma, c\right)$; at this time, $g\left(q_{i t} ; \gamma, c_{1}, c_{2}\right)=[1+$ $\left.\exp \left[-\gamma\left(q_{i t}-c_{1}\right)\left(q_{i t}-c_{2}\right)\right]\right]^{-1}$, the conversion function has the minimum value in $\left(\left(c_{1}+c_{2}\right) / 2\right)$, and its corresponding mechanism is the intermediate mechanism, while $\lim _{q_{i t} \longrightarrow+\infty} g\left(q_{i t} ; \gamma, c_{1}, c_{2}\right)=1$. Combined with the theoretical analysis of the impact of the electricity price of urban households on electricity consumption, the following analysis model is constructed:

$$
\begin{aligned}
\text { elec }= & \mu_{1 t}+\sum \beta_{1 t} \times x_{1 t}+\beta_{1 t}^{\prime} g\left(\text { income } ; \gamma_{1}, c_{1}\right) \times x_{1 t}+u_{1 t}, \\
\text { elec }= & \mu_{2 t}+\sum \beta_{2 t} \times x_{2 t}+\beta_{2 t}^{\prime} g\left(\text { urbanization; } \gamma_{1}, c_{1}\right) \\
& \times x_{2 t}+u_{2 t},
\end{aligned}
$$

where $x_{1 t}=(\mathrm{ecp}$, income, CPI, ids, rain, temp, pca) is the explanatory variable matrix consisting of the core explanatory variable, the transition variable, and the control variable. $\beta_{1 t}=\left(\beta_{11}, \beta_{12}, \beta_{13}, \beta_{14}, \beta_{15}, \beta_{16}, \beta_{17}\right)$ is the model linear estimation coefficient of the explanatory variable in the PSTR model. $\beta_{1 t}^{\prime}=\left(\beta_{11}^{\prime}, \beta_{12}^{\prime}, \beta_{13}^{\prime}, \beta_{14}^{\prime}, \beta_{15}^{\prime}, \beta_{16}^{\prime}, \beta_{17}^{\prime}\right)$ is the model nonlinear estimation coefficient of the explanatory variable in the PSTR model. $x_{2 t}=$ (ecp, income, CPI, ids, rain, temp, pca) is an explanatory variable matrix consisting of core explanatory variable, transition variable, and control variable. $\beta_{2 t}=\left(\beta_{21}, \beta_{22}, \beta_{23}, \beta_{24}, \beta_{25}, \beta_{26}, \beta_{27}\right)$ is the model linear estimation coefficient of explanatory variable in PSTR model, and $\beta_{2 t}^{\prime}=\left(\hat{\beta}_{21}^{\prime}, \hat{\beta}_{22}^{\prime}, \beta_{23}^{\prime}, \beta_{24}^{\prime}, \beta_{25}^{\prime}, \beta_{26}^{\prime}, \beta_{27}^{\prime}\right)$ is the model nonlinear estimation coefficient of explanatory variable in PSTR model. Among them, the value range of urbanization rate of transition variable is between $(0,1)$, so the logarithm is mapped to $[-\propto,+\infty]$ in the process of empirical analysis to facilitate the discussion of results. The parameter estimation of PSTR model can effectively overcome the problem of parameter heterogeneity and obtain relatively reliable and stable estimation results. For PSTR model, the estimate of parameter is obtained by nonlinear least square method, and the initial slope coefficient and location parameters of the transition function are obtained by seeking high-precision analog degradation, while the NLS method is used to estimate the nonlinear parameters of the model.

\subsection{Variable Selection}

3.2.1. Explained Variable. In this paper, the electricity demand of household energy consumption of urban residents is taken as the main indicator to measure the energy consumption level of urban residents, and it is denoted as elec. The electricity consumption of urban residents is selected from 30 provincial capitals and key cities (such as Shenzhen and Ningbo). In fact, in the process of urbanization development, electricity consumption has become the main type of household energy consumption, such as cooking and heating. On the other hand, rural household energy consumption is also gradually shifting from biomass (firewood) to clean energy consumption such as electricity. Therefore, electricity consumption becomes the main behavioral characteristic of household energy consumption.

3.2.2. Core Explanatory Variable. The core explanatory variable in this paper is electricity sales price, denoted as ecp. The electricity sales price is expressed by the prevailing sales price of each province in the country. The relationship between electricity price and demand is complex due to the rigid characteristics of power demand. The increase of residents' income makes energy more affordable and accessible. In addition, urbanization development changes energy behavior, to some extent, in respect of alternative energy sources, especially the increase in electricity consumption, to replace unclean energy sources. This in turn makes the relationship between electricity price and its consumption much more complex. In this paper, we try to investigate how the price drives electricity demands in household sector, at different scenarios.

3.2.3. Transition Variable. In this paper, the per capita disposable income (income) and urbanization rate (urbanization) are selected as the transition variables in PSTR model. Because of the typical urban-rural duality of China's economic development, there are obvious regional characteristics in terms of income and urbanization at a national scale. Per capita disposable income of residents in the eastern coastal regions is generally higher than that in the central and western regions. The urbanization is still developed slowly in the western region, especially in the remote underdeveloped areas. Therefore, to comprehensively analyze the regional differences in the impact of electricity sales price on the electricity consumption of urban residents in China, it is necessary to analyze the state characteristics of the relationship between the electricity consumption and electricity sales price of urban residents under different incomes and different urbanization levels.

3.2.4. Control Variables. The electricity consumption demand is closely interconnected with the economy, society, 
and environment. Among them, in respect of economic factors, the growth of income level and expenditure level has greatly driven the consumption, so that the power consumption demand has also been increased. The optimization and adjustment of industrial structure reflect the level and quality of social and economic development. The adjustment of industrial structure and the transformation of national economy to service industry will play a role in promoting the reduction of power consumption to a certain extent. In respect of environmental factors, the unique temperature difference between the north and the south and the rainfall difference between the east and the west have a significant seasonal impact on the annual electricity consumption of urban residents. To fully investigate the impact of these factors on the household electricity consumption of urban residents in China, this paper has selected CPI, industrial structure (ids), urban annual average rainfall (rain), urban annual average temperature (temp), and per capita housing construction area of major cities (PCA) as the control variables of PSTR model analysis.

3.3. Data Sources and Descriptive Statistics. Table 1 presents statistical characteristics of variables selected in this study. The explained variable is urban household electricity consumption. The core explanatory variable is the electricity sales price, and the transition variables are urban residents' per capita disposable income and urbanization rate, while control variables include industrial structure (proportion of secondary industry to total GDP), housing construction area, CPI (consumer price index), annual average temperature, and annual average rainfall. All data are from relevant statistical yearbooks of 30 provincial capitals of China (including the statistical yearbooks of cities and the statistical yearbooks of economic development of different provinces, excluding Taiwan, Hong Kong, Macao, and Tibet).

\section{Empirical Test and Analysis}

4.1. Linear Test and Residual Nonlinear Test. The regression analysis of PSTR model is required to meet the three-step assumptions. First, test the establishment of the linear and nonlinear relationship of the model and the number of transition functions. Second, determine the position parameters of the PSTR model. Third, calculate the initial values of the smoothing parameters and the position parameters based on the above. Table 2 shows the verification for basic hypothesis of the model herein. The test results show that the null hypothesis H0: $r=0$ passes the significance test at a significant level of $1 \%$, while the null hypothesis $\mathrm{H} 1: r=1$ is not significant at the 5\% level. Therefore, the models are nonlinear. In addition, the number of transition functions is 1; that is, $r=1$. At the same time, the values of AIC and BIC of all models $m=1$ are less than the test value of $m=2$, so the constructed model has a position parameter.

\subsection{Effect of Electricity Sales Price on Urban Household Electricity Consumption under Residents' per Capita}

Disposable Income. Table 3 shows the results. Models 1-4 show regression results of the models with regard to influence of electricity sales price on urban household electricity consumption nationwide and in eastern, central, and western regions in the context of urban residents' per capita disposable income between different regions. It can be seen that most of the factors influencing urban household electricity consumption pass the significance test. Herein, the influence of electricity sales price on urban household electricity consumption is explained by regions from the perspective of regional per capita income differences.

From a nationwide perspective, the position parameter for nonlinear conversion of PSTR model is RMB 9.91 thousand, indicating that nonlinear income threshold value of urban household electricity consumption based on the influence of electricity sales price is RMB 9.91 thousand. Therefore, there are two transition mechanisms in the model. When per capita disposable income is less than RMB 9.91 thousand, the model is in low mechanism, and the coefficient of influence of electricity sales price on urban household electricity consumption is 0.42 . When per capita disposable income is higher than RMB 9.91 thousand, the model is in high mechanism, and the coefficient is -2.38 . On the one hand, the correlation between electricity sales price and electricity consumption has turned from positive to negative as the urban residents' per capita income level increases. On the other hand, the influence of urban residents' per capita disposable income level on electricity consumption has also changed from positive to negative with the increase of income level. The coefficient of influence of urban residents' per capita income on electricity consumption is 0.64 when the model is in low mechanism and -0.27 when the model is in high mechanism. Therefore, urban residents' per capita disposable income has an effect on the selectivity of household electricity consumption. Herein, it is believed that the increase in per capita disposable income has enhanced the diversity of selections of urban household energy consumption, and there are alternative energy products for electricity consumption.

For eastern region, the position parameter for the nonlinear conversion of the PSTR model is RMB 9.49 thousand, indicating that the nonlinear income threshold value of the electricity sales price that affects urban household electricity consumption in the eastern region is RMB 9.49 thousand. Similar to the national situation, there are two transition mechanisms in the eastern region model. When the per capita disposable income is lower than RMB 9.49 thousand, the model is in low mechanism, and there is a negative linear correlation between electricity sales price and urban household electricity consumption $(-0.23)$. When the per capita disposable income is higher than RMB 9.49 thousand, there is a positive nonlinear correlation between electricity sales price and urban household electricity consumption (1.96). For residents' per capita disposable income under the two mechanisms, urban household electricity consumption decreases as the residents' disposable income level increases. The influence coefficient of residents' disposable income on urban household electricity consumption is -0.24 when the model is in low mechanism and -0.92 with 
TABLE 1: Descriptive statistical characteristics of variables.

\begin{tabular}{|c|c|c|c|c|c|}
\hline Variable description & Obs. & Mean & Std. Dev. & Min & Max \\
\hline Household energy consumption & 420 & 428098 & 401371 & 21293 & 2100000 \\
\hline Electricity sales price & 420 & 502.361 & 66.676 & 334.000 & 694.560 \\
\hline Income & 420 & 25740.840 & 11664.100 & 8397 & 61172 \\
\hline Urbanization & 420 & 52.646 & 14.255 & 26.870 & 89.600 \\
\hline Industrial structure & 420 & 42.919 & 8.530 & 18.100 & 60.100 \\
\hline Per capita housing construction area & 420 & 1101.602 & 1591.397 & 45.570 & 13755.900 \\
\hline CPI & 420 & 102.611 & 1.747 & 97.510 & 108.400 \\
\hline Annual average temperature & 420 & 14.582 & 5.074 & 4.283 & 25.358 \\
\hline Annual average rainfall & 420 & 79.162 & 44.339 & 9.363 & 244.975 \\
\hline
\end{tabular}

TABLE 2: Linear test and residual nonlinear test results.

\begin{tabular}{|c|c|c|c|c|c|c|c|c|c|c|}
\hline \multirow{2}{*}{ Model } & \multicolumn{3}{|c|}{$\mathrm{H}_{0}: r=0, \mathrm{H}_{1}: r=1$} & \multicolumn{3}{|c|}{$\mathrm{H}_{1}: r=1, \mathrm{H}_{2}: r=2$} & \multicolumn{2}{|c|}{ AIC } & \multicolumn{2}{|c|}{$\mathrm{BIC}$} \\
\hline & LM & LMF & LRT & LM & LMF & LRT & $m=1$ & $m=2$ & $m=1$ & $m=2$ \\
\hline M1 & $85.32(0.00)$ & $4.48(0.00)$ & $95.38(0.00)$ & $6.21(0.51)$ & $0.79(0.60)$ & $6.26(0.51)$ & 3.54 & 3.68 & 4.23 & 4.28 \\
\hline M2 & $79.83(0.00)$ & $6.89(0.00)$ & $118.23(0.00)$ & $13.77(0.05)$ & $1.70(0.12)$ & $14.50(0.43)$ & 4.21 & 4.49 & 4.98 & 5.20 \\
\hline M3 & $55.42(0.00)$ & $3.87(0.00)$ & $76.49(0.00)$ & $21.86(0.00)$ & $2.88(0.01)$ & $24.32(0.00)$ & 4.21 & 4.37 & 4.29 & 4.41 \\
\hline M4 & $53.72(0.00)$ & $3.04(0.00)$ & $65.08(0.00)$ & $20.47(0.00)$ & $2.67(0.01)$ & $21.87(0.00)$ & 5.45 & 5.87 & 6.82 & 7.01 \\
\hline M5 & $71.76(0.00)$ & $3.62(0.00)$ & $78.77(0.00)$ & $13.35(0.06)$ & $1.73(0.10)$ & $13.57(0.06)$ & 4.01 & 4.65 & 5.21 & 5.45 \\
\hline M6 & $78.64(0.00)$ & $6.65(0.00)$ & $115.48(0.00)$ & $25.19(0.00)$ & $3.42(0.00)$ & $27.78(0.00)$ & 4.23 & 4.58 & 4.88 & 4.98 \\
\hline M7 & $73.52(0.00)$ & $7.55(0.00)$ & $119.65(0.00)$ & $27.65(0.00)$ & $3.89(0.00)$ & $31.76(0.00)$ & 4.30 & 4.53 & 5.32 & 5.67 \\
\hline M8 & $60.52(0.00)$ & $3.68(0.00)$ & $75.12(0.00)$ & $7.07(0.42)$ & $0.84(0.55)$ & $7.23(0.41)$ & 5.61 & 5.81 & 6.01 & 6.42 \\
\hline
\end{tabular}

TABLE 3: Model parameter estimation results (in the context of urban residents' disposable income change).

\begin{tabular}{lcccc}
\hline & M1 & M2 & M3 & M4 \\
\hline$\beta_{11}$ & $0.42^{*}(1.41)$ & $-0.23^{*}(-1.71)$ & $\left.-39.05^{* * *}--2.72\right)$ & $0.62^{* * *}(7.07)$ \\
$\beta_{12}$ & $0.64^{* * *}(2.34)$ & $-0.24^{* * *}(-2.36)$ & $10.24^{*}(1.38)$ & $0.71^{* * *}(2.29)$ \\
$\beta_{13}$ & $0.25^{*}(1.53)$ & $0.02(0.69)$ & $-7.09^{* * *}(-2.32)$ & $0.04(0.23)$ \\
$\beta_{14}$ & $0.12^{* * *}(4.37)$ & $0.83(0.85)$ & $0.95(1.03)$ & $-96.91^{* * *}(-2.96)$ \\
$\beta_{15}$ & $-1.44^{* * *}(-2.48)$ & $-0.01(-0.02)$ & $-3.07^{* * *}(-2.22)$ & $-0.61(-0.92)$ \\
$\beta_{16}$ & $-0.27^{* * *}(-2.36)$ & $0.12(0.89)$ & $0.31(0.21)$ & $-0.05(-0.38)$ \\
$\beta_{17}$ & $-0.20^{* * *}(-3.41)$ & $1.56(1.12)$ & $7.82^{*}(1.93)$ & $-0.07^{*}(-1.42)$ \\
$\beta_{1}$ & $-2.80^{*}(-1.94)$ & $2.19^{* *}(2.13)$ & $-17.12(-1.26)$ & $0.67(0.37)$ \\
$\beta_{12}^{\prime}$ & $-0.91(-1.18)$ & $-0.68^{* * *}(-2.83)$ & $11.38^{* *}(2.09)$ & $16.05^{*}(1.65)$ \\
$\beta_{13}^{\prime}$ & $-1.46^{* * *}(-6.23)$ & $-0.16^{*}(-1.73)$ & $-1.60(-0.97)$ & $-3.02^{* * *}(-2.56)$ \\
$\beta_{14}^{\prime}$ & $-0.05(-1.07)$ & $-2.04^{*}(-1.85)$ & $177.60^{* * *}(2.98)$ & $1.00(1.54)$ \\
$\beta_{15}^{\prime}$ & $2.37(2.87)$ & $0.81(0.86)$ & $5.73^{* *}(2.33)$ & $-23.26(-1.38)$ \\
$\beta_{16}^{\prime}$ & $0.67^{* * *}(4.76)$ & $-0.01(-0.34)$ & $-0.58(-0.23)$ & $1.13^{*}(1.81)$ \\
$\beta_{17}^{\prime}$ & $0.29^{* * *}(2.78)$ & $-0.51(-0.22)$ & 0.17 & $0.57(1.21)$ \\
$\gamma_{1}$ & 1.77 & 1.51 & 8.62 & 10.52 \\
$c_{1}$ & 9.91 & 9.49 & 10.60 \\
\hline
\end{tabular}

Note: ${ }^{* * *},{ }^{* *},{ }^{*}$ significant at the levels of $1 \%, 5 \%$, and $10 \%$, respectively. The $t$ values for parameter estimates are in parentheses.

the model in high mechanism. Herein, it is believed that the positive relationship between electricity sales price and urban household electricity consumption may be partly due to the insensitivity of step tariff to electricity demand under the conditions of high income, and high-income levels have stimulated the potential of urban households in energy consumption at specific stages of income levels.

For the central region, the threshold value of the influence of urban residents' per capita disposable income is RMB 8.62 thousand. There are two transition mechanisms for the models with regard to the influence of electricity sales price on urban household electricity consumption in central region. The model is in low mechanism when the residents' per capita disposable income is less than RMB 8.62 thousand and in high mechanism when the residents' per capita disposable income is greater than RMB 8.62 thousand. In central region, the slope changes gently as the conversion degree is small (the value of conversion degree is 0.17 ). When the residents' disposable income level is low, the relationship between the electricity sales price and the urban household electricity consumption is negative, but the degree of this negative relationship gradually decreases as per 
capita disposable income increases. Under both mechanisms, the relationship between electricity sales price and urban household electricity consumption in central region is linearly negative and nonlinearly negative. According to the separate investigation for the influence of the residents' disposable income on urban household electricity consumption, residents' disposable income and urban household electricity consumption are positively correlated when the model is in low mechanism. The nonlinear relationship between them shows a negative correlation (coefficient is -6.88) when the model is in high mechanism.

For western region, the threshold value of effect of urban residents' per capita disposable income is RMB 10.52 thousand. The threshold value of the electricity sales price that affects the urban household electricity consumption in this region is RMB 10.60 thousand. There are two transition mechanisms. When per capita disposable income is less than RMB 10.60 thousand, the model is in low-mechanism state, and at this point, the linear coefficient of the effect of electricity sales price on the urban household electricity consumption is 0.62 . When the per capita disposable income is greater than RMB 10.60 thousand, the model is in highmechanism state, and at this point, the linear coefficient of the effect of electricity sales price on the urban household electricity consumption is 1.29 . There is a positive correlation between electricity sales price and urban household electricity consumption under the two mechanisms. Urban household electricity consumption has gradually increased in western region as the income level increases. In addition, it can be found that the influence of residents' disposable income level is larger than that of the electricity sales price on household electricity consumption under both mechanisms. Therefore, it can be predicted that income level in western region is still the main factor that determines urban household energy consumption with the implementation of energy conservation, emission reduction, and new energy policies, and the price sensitivity of energy consumption is generally low.

Figure 1 shows the transition functions of regression results, corresponding to the models in Table 3. Model 1 to Model 4 are transition functions of regression results in terms of the influence of electricity sales price on urban household electricity consumption throughout the country and eastern region, central region, and western region considering the urban residents' per capita disposable income among different regions. From the perspective of regional analysis, some observations of the models are between the low and high mechanisms of the models. Therefore, there are two mechanisms in these models with regard to the influence of the electricity sales price on urban household electricity consumption in the context of urban households' per capita disposable income. From the transition function graph shown in Figure 1, it is found that the degrees of the model transition throughout the country and in eastern region and central region are lower than those in the western region, which are $1.77,1.51$, and 0.17 , respectively. The slope of the transition function changes more gently. In the western region, the degree of transition is 10.52, the slope of the transition function changes drastically, and most of the observations are in the lowmechanism state of the model.

\subsection{Effect of Electricity Sales Price on Urban Household} Electricity Consumption under Urbanization Rate. Table 4 shows the estimate results of the effects of electricity sales price on urban household electricity consumption. Models 5-8 are the regression results about the relationship between electricity sales price and urban household electricity consumption throughout the country and in eastern region, central region, and western region under urbanization development in different regions. We find that most of the factors influencing urban household electricity consumption have passed the significance test. This will explain the influence of electricity sales price on urban household electricity consumption in regions from the perspective of progress differences in regional urbanization development.

The effect of electricity sales price on urban household electricity consumption is seen from the background of urbanization development nationwide. There are two transition mechanisms for Model 5. The threshold value of urbanization is urbanization $=e^{-3.79}$. The influencing coefficient of electricity sales price on the urban household electricity consumption is 0.39 when it is less than the threshold value and 1.28 when it is greater than the threshold value. This shows that the total urban household electricity consumption has continued to increase with urbanization development. It is found that urbanization development positively affects urban household electricity consumption (coefficient is 1.71) in the low mechanisms of the model. The higher the level of urbanization is, the greater the growth in urban household electricity consumption is. In the high mechanisms of the model, both have nonlinear positive correlation (coefficient is 1.02). It can be seen that there is significant nonlinear relationship between electricity sales price and urban household electricity consumption nationwide. In addition, urbanization positively drives the urban household electricity consumption and promotes the growth of total electricity consumption.

The regression results show that there are two transition mechanisms for Model 6. The threshold value of urbanization in the eastern region is urbanization $=e^{-4.05}$. There is always a positive correlation between the electricity sales price and the urban household electricity consumption. Under the two mechanisms, the coefficient of the influence of electricity sales price on urban household electricity consumption increased from 2.33 to 2.95 , indicating that the effect has gradually increased as the urbanization rate rises. In eastern region, the influence of urbanization development on urban household electricity consumption has changed from negative (coefficient is -0.54 ) to positive (coefficient is 1.94) in the low mechanism. This shows that urbanization development has promoted the growth of urban household electricity consumption, and it has become an important driving force of growth in urban household energy consumption.

The regression results also show that there are two transition mechanisms in Model 7. The threshold value of 

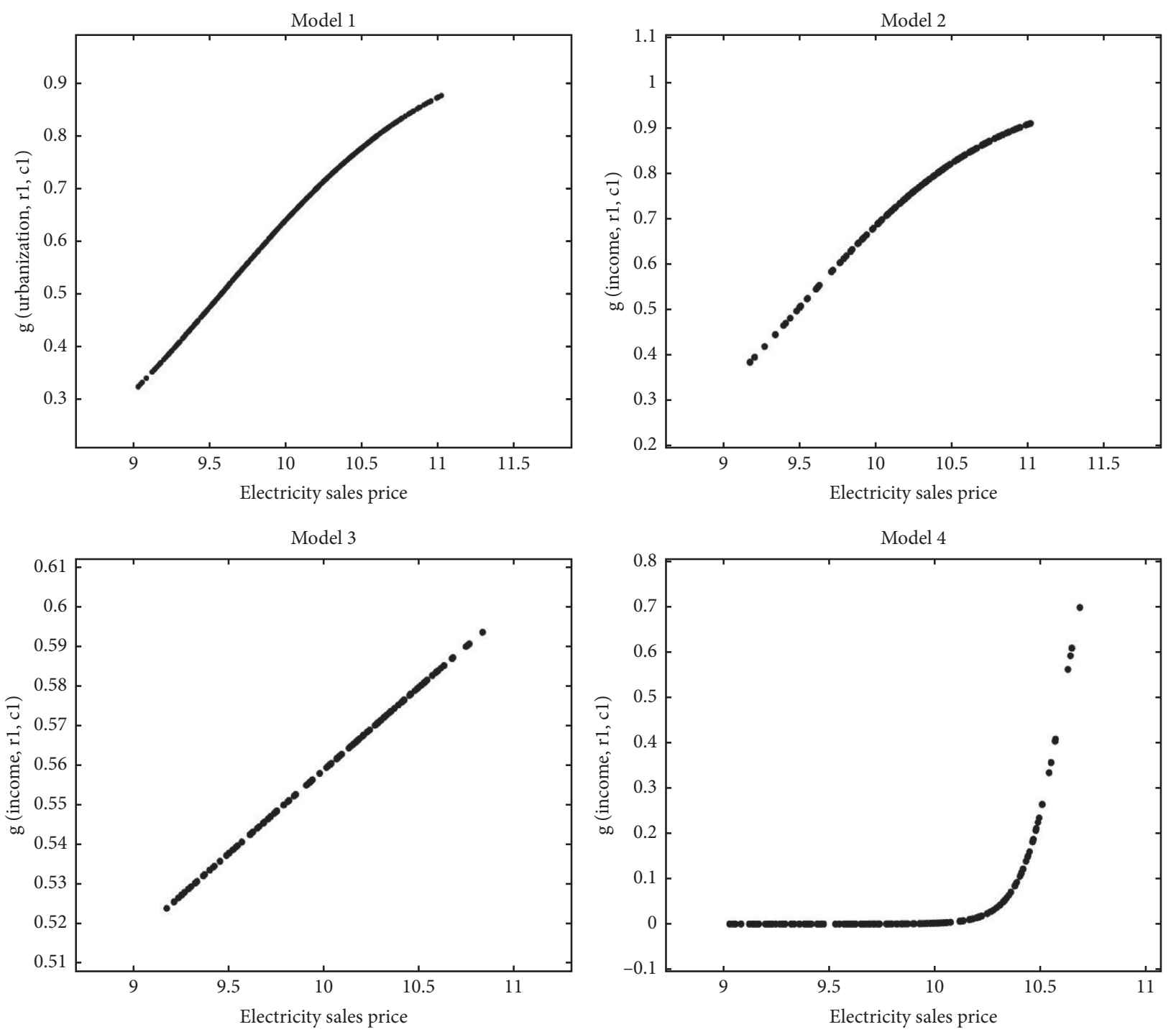

Figure 1: Transition functions of different model regression results in the context of urban households' per capita disposable income.

urbanization in central region is urbanization $=e^{-3.69}$. At different stages of urbanization development, the electricity sales price positively affects the urban household energy consumption. With continuous improvement of urbanization rate, the total urban household electricity consumption has continued to increase. Regression results show that the coefficient of the effect of electricity sales price on urban household electricity consumption is 1.69 under a highmechanism state. From the fact that urbanization affects the total urban household electricity consumption, it can be seen that urbanization development has promoted the growth of electricity consumption. The coefficient is 2.18 when the model is in low mechanism and 1.27 when the model is in high mechanism. Therefore, electricity sales price and urbanization level are positively correlated with urban household electricity consumption in central region whether it is a low-mechanism linear relationship or a high-mechanism nonlinear relationship.

The regression results show that there are two transition mechanisms for Model 8, and the threshold value of urbanization in western region is urbanization $=e^{-3.91}$. In western region, the coefficient of influence of electricity sales price on urban household electricity consumption is 1.79 when the model is in low mechanism and 0.29 when the model is high mechanism. It can be seen that the electricity sales price remains positively correlated to the urban household electricity consumption with urbanization development. However, its degrees of influence are different in the two states. The role of urbanization in promoting household electricity consumption growth has gradually increased as the urbanization rate rises. It is found that urbanization development has a positive effect on the growth of urban household electricity consumption through both mechanisms. On the one hand, urbanization development has changed the energy consumption structure of rural households after they became urban households. Under the guidance of policies that promote clean energy consumption, electricity has become a rigid energy source for urban household in several choices. On the other hand, the improvement of urbanization has increased the total demand 
TABLE 4: Model parameter estimates (in the context of urbanization change).

\begin{tabular}{|c|c|c|c|c|}
\hline & M5 & M6 & M7 & M8 \\
\hline$\beta_{21}$ & $0.39^{*}(1.52)$ & $2.33^{* * *}(5.34)$ & $0.37^{*}(1.73)$ & $1.79^{* * *}(5.92)$ \\
\hline$\beta_{22}$ & $1.71^{* * *}(8.30)$ & $\begin{array}{l}-0.54^{* *} \\
(-2.07)\end{array}$ & $2.18^{* * *}(7.87)$ & $0.27(0.87)$ \\
\hline$\beta_{23}$ & $\begin{array}{c}-0.95^{* * *} \\
(-3.42)\end{array}$ & $\begin{array}{c}-3.26^{* * *} \\
(-8.59)\end{array}$ & $\begin{array}{c}-1.53^{* * *} \\
(-3.94)\end{array}$ & $0.18^{* * *}(4.07)$ \\
\hline$\beta_{24}$ & $0.26^{* * *}(4.66)$ & $0.07(1.04)$ & $0.58^{* * *}(6.37)$ & $0.14^{* * *}(3.88)$ \\
\hline$\beta_{25}$ & $0.70(1.24)$ & $4.55^{* * *}(4.97)$ & $-0.47(-0.48)$ & $-0.26(-0.38)$ \\
\hline$\beta_{26}$ & $\begin{array}{c}-0.54^{* * *} \\
(-3.40)\end{array}$ & $-0.28(-0.52)$ & $2.21^{* * *}(3.26)$ & $0.18(1.02)$ \\
\hline$\beta_{27}$ & $-0.08(-1.24)$ & $-0.04(-0.23)$ & $0.01(0.08)$ & $\begin{array}{c}-0.18^{* * *} \\
(-3.05)\end{array}$ \\
\hline$\beta_{21}^{\prime}$ & $0.89^{* * *}(3.22)$ & $0.62(1.05)$ & $1.32^{* * *}(4.11)$ & $\begin{array}{c}-1.50^{* * *} \\
(-3.66)\end{array}$ \\
\hline$\beta_{22}^{\prime}$ & $\begin{array}{l}-0.69^{* *} \\
(-2.83)\end{array}$ & $2.48^{* * *}(5.55)$ & $-0.91^{* *}(-2.18)$ & $2.55^{* * *}(5.67)$ \\
\hline$\beta_{23}^{\prime}$ & $-0.14(-0.51)$ & $2.56^{* * *}(5.97)$ & $1.43^{* * *}(3.21)$ & $\begin{array}{c}-1.74^{* * *} \\
(-5.24)\end{array}$ \\
\hline$\beta_{24}^{\prime}$ & $\begin{array}{l}-0.12^{* *} \\
(-2.12)\end{array}$ & $-0.20^{*}(-2.12)$ & $\begin{array}{c}-0.39^{* * *} \\
(-4.17)\end{array}$ & $\begin{array}{l}-0.12^{* *} \\
(-2.01)\end{array}$ \\
\hline$\beta_{25}^{\prime}$ & $0.09(0.25)$ & $\begin{array}{c}-6.39^{* * *} \\
(-8.35)\end{array}$ & $0.86^{*}(1.53)$ & $-0.60(-1.00)$ \\
\hline$\beta_{26}^{\prime}$ & $0.59^{* * *}(4.78)$ & $0.88^{*}(1.57)$ & $-2.22(-3.43)$ & $-0.19^{*}(-1.15)$ \\
\hline$\beta_{27}^{\prime}$ & $0.09^{*}(1.44)$ & $0.09(0.51)$ & $-0.02(-0.15)$ & $0.32^{* * *}(3.80)$ \\
\hline$\gamma_{2}$ & 70.27 & 15.52 & 57.85 & 19.10 \\
\hline$c_{2}$ & 3.79 & 4.05 & 3.69 & 3.91 \\
\hline
\end{tabular}

Note. ${ }^{* * *},{ }^{* *},{ }^{*}$ significant at the levels of $1 \%, 5 \%$, and $10 \%$, respectively. The $t$ values for parameter estimates are in parentheses.

for energy consumption in the original urban households. Electricity is the main source of energy for urban households. The increase in urbanization level, the convenience in energy acquisition, the further improvement of quality of life, and the diversity of household electrical appliances have promoted the further increase of the total urban household electricity consumption.

Figure 2 shows the transition function of the regression results of the models in Table 4. Models 5-8 are transition functions of regression results in terms of the influence of electricity sales price on the urban household electricity consumption nationwide and in eastern, central, and western regions considering the urbanization development levels among different regions. From regional perspective, some observations of the models are between the low and high mechanisms. Therefore, there are two mechanisms with regard to the influence of the electricity sales price on urban household electricity consumption under different levels of urbanization development. From the transition function graph shown in Figure 2, it can be seen that the degree of model transition nationwide and in eastern and central regions is lower than that in the western regions, which are $70.27,15.52,57.85$, and 19.1, respectively. In comparison, the slopes of the transition functions change gently in the eastern and western regions, while those nationwide and in the central region change sharply. The influence of the background of urbanization development on the relationship between electricity sales prices and urban household electricity consumption nationwide and in the central region is more significant than those in the eastern and western regions.

\section{Empirical Discussion and Policy Analysis}

Through empirical analysis, this paper argues that there is a complex nonlinear relationship between electricity sales prices and urban household electricity consumption. This complex nonlinear relationship shows different influencing directions and degrees under different income levels and urbanization development. In the following, the specific reasons for the formation of research conclusions on electricity sales prices and urban household electricity consumption and the implications for policies are discussed in detail from perspectives of regional differences in both residents' disposable income and urbanization development.

Models 1-4 are for investigating the relationship between the electricity sales price, residents' disposable income, and urban household electricity consumption under changes in the residents' disposable income. Nationwide, electricity sales prices and residents' income level are negatively correlated to the urban household electricity consumption. Given the difference in residents' income, electricity sales price is positively correlated to the urban household electricity consumption in eastern and western regions but negatively correlated to urban household electricity consumption in central region. These results can be explained from the following perspectives. First, environmental regulatory policies cause regional differences. In recent years, the production and consumption of clean energy have been advocated nationwide. As a clean energy, electricity is an alternative to most energy categories. Especially in urban living environments, electricity consumption, as a major source of household energy consumption, is relatively insensitive to electricity sale price. Electricity becomes a "rigid-demanded" consumer product. Second, from the development trend of electricity demand, the rise in production costs has led to increase in electricity sales price. The promotion effect of cost is greater than that of growth in demand for electricity consumption.

In addition, income is a very important influential factor for household electricity consumption. As is well known, Chinese economic development holds very obvious regional differences. Eastern and southern coastal regions are considered traditional developed areas. Central part of China is defined as the less developed area, and west region, especially for northwest part of China, is undeveloped area. In fact, from the perspective of the resource endowment of regional development, the differences in economic development between the east, the central, and the west regions are fully reflected in the level of per capita income. Regional differences, to some extent, determine residents' consumption behavior. This paper shows the practical significance of income difference for consumption relationship. Therefore, household energy policies should be flexible enough to promote equity in energy access between regions.

Models 5-8 are for investigating the relationship between electricity sales prices, urbanization levels, and urban household electricity consumption in the context of 

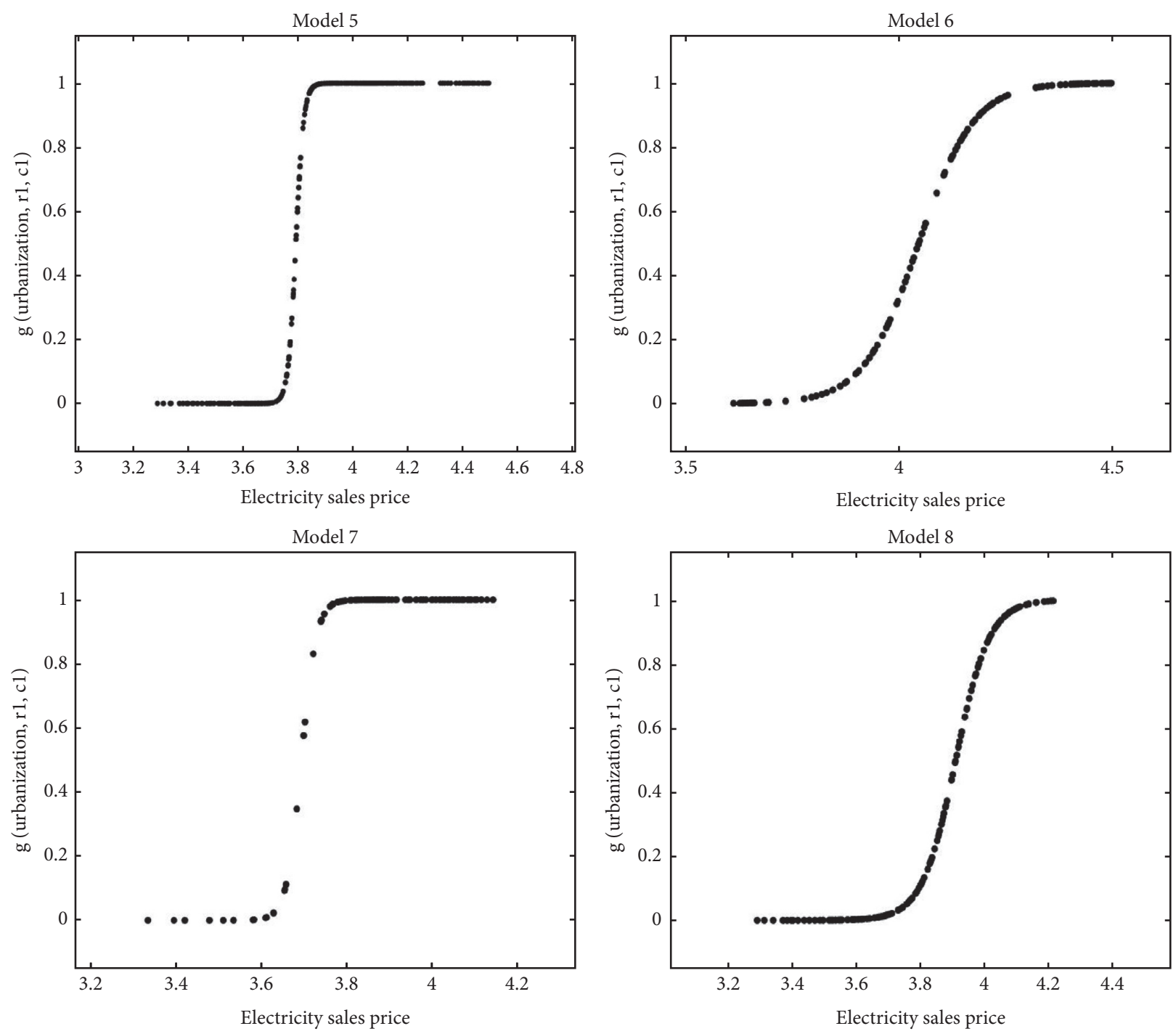

FIgURE 2: Transition functions of regression results of different models in the context of urbanization development.

urbanization development. The regression results of the models show that electricity sales price remains positively correlated to the urban household electricity consumption nationwide in the context of regional differences in urbanization. The coefficients of influence of electricity sales price on urban household electricity consumption are the highest in eastern region and the lowest in western region. However, the positive influence of urbanization development on urban household electricity consumption is the strongest in western region. The reasons for the positive relationship between the electricity sales price and the urban household electricity consumption in the context of urbanization may be as follows: First, the process of urbanization development has changed the role of the original residents in life, which is represented by typical demolition and urban village reconstruction. The change of role has reduced the habitual household energy option and choice range of the original residents. Second, urbanization development has changed the characteristics of overall growth in urban household energy consumption. The advancement of urbanization as a whole has improved the quality of life of residents and promoted the general increase in the absolute amount of energy demanded by urban households. Furthermore, the incremental demand for household electricity-consuming products has further promoted the sustainable growth in total electricity consumption.

Furthermore, China's urbanization development still has a strong momentum. On the one hand, urbanization development has changed the residents' energy consumption habits and energy structure, especially for the shifting from high-carbon energy sources to cleaner ones. On the other hand, the development of urbanization is a manifestation of economic development. However, regional urbanization shows certain stage characteristic due to the different development resource endowment. This in turn plays a dominant role in affecting household energy consumption. Therefore, one very important suggestive finding is that the effectiveness of household energy policies should be fully considered at different stages of economic development and their phase characteristics. 
In short, per capita disposable income and the level of urbanization are the key factors affecting urban household electricity consumption. The relationship between electricity sales price and total urban household electricity consumption is generally affected by regional differences. The increase in per capita disposable income has improved the actual affordability of urban household electricity consumption and further stimulated the potential of the growth of household energy consumption. The process of urbanization has changed not only the residents "energy consumption habits, but also the range of residents" energy choices. Based on the above analysis, the special manifestations of the relationship between reference variables at different regional levels need to be considered in the research of policies on household energy consumption. Starting from the basic variable relationship, comprehensive consideration is given to the context factors for the variable relationship. This paper mainly considers the regional differences characterized by the two factors of residents' disposable income and urbanization level.

\section{Conclusions}

This paper analyzes nonlinear relationship between electricity sales prices and urban household electricity consumption using PSTR approach. Considering the regional differences in the relationship between variables studied, this paper investigates systematically the complex relationship between the two and their specific forms under residents' disposable income and urbanization rate. To this direction, two sets of panel are constructed for smooth transition of regression models to explore the nonlinear relationship, with residents' disposable income and urbanization rates as converted variables. The research concludes that the degrees and models of influence of electricity sales price on urban household electricity consumption are different in the eastern, central, and western areas of China due to differences in income and urbanization. Such different relationship between variables provides an important research reference and decision basis for the Chinese government to implement energy policy and promote the synergy of policy benefits between regions.

\section{Data Availability}

The data used to support the findings of this study are included within the article.

\section{Conflicts of Interest}

The authors declare that there are no conflicts of interest regarding the publication of this paper.

\section{Acknowledgments}

The paper was supported by the National Natural Science Foundation of China (no. 71874133).

\section{References}

[1] M. Zhang and C. Bai, "Exploring the influencing factors and decoupling state of residential energy consumption in Shandong," Journal of Cleaner Production, vol. 194, pp. 253-262, 2018.

[2] M. Zhang and F. Guo, "Analysis of rural residential commercial energy consumption in China," Energy, vol. 52, pp. 222-229, 2013.

[3] X. Y. Zheng, Research Report on Chinese Household Energy Consumption, Science Press, Beijing, China, 2016, in Chinese.

[4] M. Zhang and B. Su, “Assessing China's rural household energy sustainable development using improved grouped principal component method," Energy, vol. 113, pp. 509-514, 2016.

[5] H. Xiao, Z. Ma, Z. Mi et al., "Spatio-temporal simulation of energy consumption in China's provinces based on satellite night-time light data," Applied Energy, vol. 231, pp. 10701078, 2018.

[6] S. K. Sun, J. F. Song, F. F. Wang, P. T. Wu, and Y. B. Wang, "Evaluating the impacts of socio-economic factors on regional grain virtual water flows in China using a structural equation modeling approach," Journal of Hydrology, vol. 571, pp. 132-141, 2019.

[7] Y. Zhang, J. Zhang, Z. Yang, and J. Li, "Analysis of the distribution and evolution of energy supply and demand centers of gravity in China," Energy Policy, vol. 49, pp. 695706, 2012.

[8] L. F. Jing, Y. J. Zhang, and B. Wang, "The impact of urbanization on residential energy consumption in China: an aggregated and disaggregated analysis," Renewable and Sustainable Energy Reviews, vol. 75, pp. 220-233, 2017.

[9] Y. J. Guo, Q. Zhang, K. K. Lai, Y. Q. Zhang, S. B. Wang, and W. L. Zhang, "The impact of urban transportation infrastructure on air quality," Sustainability, vol. 12, no. 14, pp. 1-23, 2020.

[10] G.-X. Liu, M. Wu, F.-R. Jia, and Q. Wang, "Material flow analysis and spatial pattern analysis of petroleum products consumption and petroleum-related $\mathrm{CO} 2$ emissions in China during 1995-2017," Journal of Cleaner Production, vol. 209, pp. 40-52, 2019.

[11] Y.-W. Su, "Residential electricity demand in Taiwan: consumption behavior and rebound effect," Energy Policy, vol. 124, pp. 36-45, 2019.

[12] Z. Yan, X. Ouyang, and K. Du, "Economy-wide estimates of energy rebound effect: evidence from China's provinces," Energy Economics, vol. 83, pp. 389-401, 2019.

[13] X. Wang, X. Wen, and C. Xie, "An evaluation of technical progress and energy rebound effects in China's iron \& steel industry,” Energy Policy, vol. 123, pp. 259-265, 2018.

[14] Y. Wu, J. Su, K. Li, and C. Sun, "Comparative study on power efficiency of China's provincial steel industry and its influencing factors," Energy, vol. 175, pp. 1009-1020, 2019.

[15] G. Liu, X. Dong, Q. Jiang, C. Dong, and J. Li, "Natural gas consumption of urban households in China and corresponding influencing factors," Energy Policy, vol. 122, pp. 17-26, 2018.

[16] Y. Yang, J. Liu, Y. Lin, and Q. Li, "The impact of urbanization on China's residential energy consumption," Structural Change and Economic Dynamics, vol. 49, pp. 170-182, 2019.

[17] Z. Wang, X. Z. Deng, X. B. Li, Q. Zhou, and H. M. Yan, "Impact analysis of government investment on water projects in the arid Gansu Province of China," Physics and Chemistry of the Earth, Parts A/B/C, vol. 79, pp. 54-66, 2015. 
[18] J. Ma, "On-grid electricity tariffs in China: development, reform and prospects," Energy Policy, vol. 39, no. 5, pp. 2633-2645, 2011.

[19] Y. Wu and L. Zhang, "Evaluation of energy saving effects of tiered electricity pricing and investigation of the energy saving willingness of residents," Energy Policy, vol. 109, pp. 208-217, 2017.

[20] P. R. Hartley, K. B. Medlock, and O. Jankovska, "Electricity reform and retail pricing in Texas," Energy Economics, vol. 80, pp. 1-11, 2019.

[21] Y. Yang and G. Meng, "A bibliometric analysis of comparative research on the evolution of international and Chinese ecological footprint research hotspots and frontiers since 2000," Ecological Indicators, vol. 102, pp. 650-665, 2019.

[22] J. Yuan, C. Zhao, S. Yu, and Z. Hu, "Electricity consumption and economic growth in China: cointegration and co-feature analysis," Energy Economics, vol. 29, no. 6, pp. 1179-1191, 2007.

[23] C. Deng, K. Li, C. Peng, and F. Han, "Analysis of technological progress and input prices on electricity consumption: evidence from China," Journal of Cleaner Production, vol. 196, pp. 1390-1406, 2018.

[24] B. Lin and C. Liu, "Why is electricity consumption inconsistent with economic growth in China?" Energy Policy, vol. 88, pp. 310-316, 2016.

[25] C. Zhang, K. Zhou, S. Yang, and Z. Shao, "Exploring the transformation and upgrading of China's economy using electricity consumption data: a VAR-VEC based model," Physica A: Statistical Mechanics and Its Applications, vol. 473, pp. 144-155, 2017.

[26] M. Li, R. Shan, M. Hernandez, V. Mallampalli, and D. PatiñoEcheverri, "Effects of population, urbanization, household size, and income on electric appliance adoption in the Chinese residential sector towards 2050," Applied Energy, vol. 236, pp. 293-306, 2019.

[27] S. Zeng, Z.-M. Chen, A. Alsaedi, and T. Hayat, "Price elasticity, block tariffs, and equity of natural gas demand in China: investigation based on household-level survey data," Journal of Cleaner Production, vol. 179, pp. 441-449, 2018.

[28] B. Ma, Y. Yu, and F. Urban, "Green transition of energy systems in rural China: national survey evidence of households' discrete choices on water heaters," Energy Policy, vol. 113, pp. 559-570, 2018.

[29] S. Wang, W. Li, H. Dincer, and S. Yuksel, "Recognitive approach to the energy policies and investments in renewable energy resources via the fuzzy hybrid models," Energies, vol. 12, p. 3645, 2019.

[30] M. R. Chertow, "The IPAT equation and its variants; changing views of technology and environmental impact," Journal of Industrial Ecology, vol. 4, no. 4, pp. 13-29, 2008.

[31] B. E. Hansen, "Threshold effects in non-dynamic panels: estimation, testing, and inference," Journal of Econometrics, vol. 93, no. 2, pp. 345-368, 1999.

[32] A. González, T. Teräsvirta, and D. Dijk, "Panel smooth transition regression models," SSE/EFI Working Paper Series in Economics and Finance, Econometric Institute, Erasmus University Rotterdam, Rotterdam, Netherlands, 2005. 